\title{
Metabolic profile changes in serum of migraine patients detected using ${ }^{1} \mathrm{H}-\mathrm{NMR}$ spectroscopy
}

\author{
Aster V. E. Harder ${ }^{1,2}$ (D), Lisanne S. Vijfhuizen ${ }^{1}$, Peter Hennemann ${ }^{3}$, Ko Willems van Dijk ${ }^{1,4,5}$, Cornelia M. van Duijn ${ }^{6,7}$, \\ Gisela M. Terwindt ${ }^{2}$ and Arn M. J. M. van den Maagdenberg ${ }^{1,2^{*}}$
}

\begin{abstract}
Background: Migraine is a common brain disorder but reliable diagnostic biomarkers in blood are still lacking. Our aim was to identify, using proton nuclear magnetic resonance ('H-NMR) spectroscopy, metabolites in serum that are associated with lifetime and active migraine by comparing metabolic profiles of patients and controls.

Methods: Fasting serum samples from 313 migraine patients and 1512 controls from the Erasmus Rucphen Family (ERF) study were available for ${ }^{1} \mathrm{H}-\mathrm{NMR}$ spectroscopy. Data was analysed using elastic net regression analysis.

Results: A total of 100 signals representing 49 different metabolites were detected in 289 cases (of which 150 active migraine patients) and 1360 controls. We were able to identify profiles consisting of 6 metabolites predictive for lifetime migraine status and 22 metabolites predictive for active migraine status. We estimated with subsequent regression models that after correction for age, sex, BMI and smoking, the association with the metabolite profile in active migraine remained. Several of the metabolites in this profile are involved in lipid, glucose and amino acid metabolism.

Conclusion: This study indicates that metabolic profiles, based on serum concentrations of several metabolites, including lipids, amino acids and metabolites of glucose metabolism, can distinguish active migraine patients from controls.
\end{abstract}

Keywords: ${ }^{1} \mathrm{H}-\mathrm{NMR}$ spectroscopy, Migraine, Biomarker, Blood, Serum

\section{Introduction}

Migraine is a common multifactorial brain disorder with a lifetime prevalence of $15-20 \%$, causing disability worldwide and a three times higher prevalence in woman compared to men [1, 2]. Migraine is characterized by recurrent episodes of severe often unilateral pulsating headache accompanied by nausea, vomiting and/or photo- and phonophobia lasting for 4-72 $\mathrm{h}$ [3]. Although much progress has been made with

\footnotetext{
* Correspondence: A.M.J.M.van_den_Maagdenberg@lumc.nl

'Departments of Human Genetics, Leiden University Medical Centre, Leiden, The Netherlands

${ }^{2}$ Department of Neurology, Leiden University Medical Centre, Leiden, The Netherlands

Full list of author information is available at the end of the article
}

unravelling its (non) genetic disease mechanisms [4], a diagnosis of migraine is still made by interview and physical examination or questionnaire, as no diagnostic biomarker is available. The lack of biomarkers, for instance in a biofluid such as blood, has also hampered the development of novel treatments.

Metabolomics is an established valuable approach for biomarker identification and has been successful in revealing the metabolic underpinnings of various human diseases [5-10]. Validated biomarkers can greatly improve diagnosis, prognosis and assessing effectivity of treatment of patients, as was already shown for several diseases other than migraine $[11,12]$. Various attempts

(c) The Author(s). 2021 Open Access This article is licensed under a Creative Commons Attribution 4.0 International License, which permits use, sharing, adaptation, distribution and reproduction in any medium or format, as long as you give appropriate credit to the original author(s) and the source, provide a link to the Creative Commons licence, and indicate if changes were made. The images or other third party material in this article are included in the article's Creative Commons licence, unless indicated otherwise in a credit line to the material. If material is not included in the article's Creative Commons licence and your intended use is not permitted by statutory regulation or exceeds the permitted use, you will need to obtain permission directly from the copyright holder. To view a copy of this licence, visit http://creativecommons.org/licenses/by/4.0/ The Creative Commons Public Domain Dedication waiver (http://creativecommons.org/publicdomain/zero/1.0/) applies to the data made available in this article, unless otherwise stated in a credit line to the data. 
have been made to identify reliable biomarkers (either clinical, genetic, radiological or biochemical) in migraine [13-16], without much success, also not for biochemical studies in blood [17] or cerebrospinal fluid [14]. Especially the identification of metabolites in an easily accessible body fluid such as peripheral blood is urgently needed [18]. When using metabolomics either a targeted approach that typically focuses on one or more related selected pathways of interest or an untargeted approach that aims to simultaneously measure as many metabolites as possible from a biological sample, can be employed. Several biochemical studies in migraine in the past two decades explored the targeted approach by examining a limited number of compounds, such as amino acids [19, 20], inflammatory markers [21-23], vasoactive neuropeptides [24-26], and (cardio) vascular risk factors [27-29], because of their presumed role in migraine pathophysiology. More recently, mainly because of the advent of novel treatment antagonizing calcitonin gene-related peptide (CGRP) or its receptor [30, 31], the field of biomarker research in peripheral blood regained interest [32], with reports of promising possible peripheral biomarkers in migraine $[33,34]$.

To search for migraine metabolite profiles in serum we used an untargeted, hypothesis-free, approach and performed high-throughput proton nuclear magnetic resonance $\left({ }^{1} \mathrm{H}-\right.$ NMR) spectroscopy. This method allows for a rapid, robust, simultaneous identification and quantification of a variety of metabolites in large numbers of samples [35]. Here we analysed metabolite profiles in serum samples of migraine patients and controls from the Erasmus Rucphen Family population, a large Dutch population-based family study from the Southwest of the Netherlands in which we previously had identified migraine cases [36]. We set out to investigate whether metabolites identified by ${ }^{1} \mathrm{H}-\mathrm{NMR}$ spectroscopy are associated with migraine by comparing metabolic profiles of migraine patients and controls in a "real-life variation" cohort.

\section{Material and methods Study population}

The study included participants from the Erasmus Rucphen Family (ERF) study [37, 38]. This study population is based on a genetically isolated community in the Southwest of the Netherlands. In brief, the ERF study population includes 3465 living descendants of 22 couples that had at least six children baptized in the community church between 1850 and 1900 . Hence, study participants were all members of a large extended pedigree and all of European ancestry. All individuals 18 years and older were invited to participate.

\section{Migraine diagnoses}

Migraine was diagnosed using a validated three-stage screening procedure [2], based on International Classification of
Headache Disorder formerly ICHD-II, now ICHD-III criteria $[3,39]$. Details on the migraine case-finding procedure have been published previously [36]. In short, first, participants filled out a five-item screening questionnaire on headache and aura symptoms. Next, screen-positives completed an additional detailed questionnaire on headache and aura symptoms. Finally, the diagnosis was validated with a telephone interview by a physician trained in headache disorders. Probable migraine patients were excluded. ERF participants who were negative for severe headache and/or migraine based on the aforementioned three-stage screening procedure were included as controls $[2,36]$. Samples from participants were collected after overnight fasting.

\section{${ }^{1} \mathrm{H}$-NMR spectroscopy metabolite profiling: data processing and quality control}

Venous blood samples had been drawn by venipuncture from the median cubital vein from participants of the ERF study after at least $8 \mathrm{~h}$ fasting period. Samples were centrifuged at $1000-2000 \mathrm{x} \mathrm{g}$ for $10 \mathrm{~min}$ at $4{ }^{\circ} \mathrm{C}$ and serum was aliquoted in cryovials and stored at $-80^{\circ} \mathrm{C}$ until further use. The ${ }^{1} \mathrm{H}$-NMR data were generated as part of a larger project and described by Vaarhorst et al. [40]. All ${ }^{1} \mathrm{H}-\mathrm{NMR}$ spectroscopy experiments had been acquired on a $600 \mathrm{MHz}$ Bruker Avance II spectrometer (Bruker) equipped with a 5-mm triple resonance inverse (TCI) cryogenic probe head with Z-gradient system and automatic tuning and matching. All experiments were recorded at $310 \mathrm{~K}$. Temperature calibration was done prior to each batch of measurements using the method of Findeisen et al. [41]. The duration of the $\pi / 2$ pulses were automatically calibrated for each individual sample using a homonuclear-gated nutation experiment on the locked and shimmed samples after automatic tuning and matching of the probe head [42].

Then, stored samples were thawed at $4{ }^{\circ} \mathrm{C}$ and mixed by inverting the containers ten times. Samples $(300 \mu \mathrm{L})$ were mixed with $300 \mu \mathrm{L} 75 \mathrm{mM}$ disodium phosphate buffer in $\mathrm{H}_{2} \mathrm{O} / \mathrm{D}_{2} \mathrm{O}(80 / 20)$ ( $\mathrm{pH} 7.4$ ), containing 6.15 $\mathrm{mM} \mathrm{NaN}_{3}$ and $4.64 \mathrm{mM}$ sodium 3-[trimethylsilyl] d4propionate (TSP), using a Gilson 215 liquid handler in combination with a Bruker SampleTrack system (Bruker, Karlsruhe, Germany). Samples were transferred into 5mm SampleJet NMR tubes (Bruker) in 96-tube racks using a modified Gilson 215 tube filling station (Gilson, Middleton, WI, USA) and kept at $6{ }^{\circ} \mathrm{C}$ on a SampleJet sample changer (Bruker) while queued for acquisition.

For water suppression pre-saturation of the water resonance with an effective field of $\gamma B_{1}=25 \mathrm{~Hz}$ was applied during the relaxation delay [43]. J-resolved spectra (JRES) [44] were recorded with a relaxation delay of $2 \mathrm{~s}$ and a total of one scan for each increment in the indirect dimension. A data matrix of $40 \times 12,288$ data points was collected covering a sweep width of $78 \times 10,000 \mathrm{~Hz}$. 
A sine-shaped window function was applied and the data was zero-filled to $256 \times 16,384$ complex data points prior to Fourier transformation. The resulting data matrix was tilted along the rows by shifting each row (k) by $0.4992 *(128-\mathrm{k})$ points and symmetrised about the central horizontal lines to compensate for the skew of the multiplets in the F1 dimension. For T2-filtered ${ }^{1} \mathrm{H}-\mathrm{NMR}$ spectra, a standard 1D Carr-Purcell-Meiboom-Gill (CPMG) pulse sequence $[45,46]$ was used with a relaxation delay of $4 \mathrm{~s}$. A pulse train of 130 refocusing pulses with individual spin echo delays of $0.6 \mathrm{~ms}$ were applied resulting in a total T2 filtering delay of $78 \mathrm{~ms}$. A total of 73,728 data points covering a spectral width of 12,019 $\mathrm{Hz}$ were collected using 16 scans. The Free Induction Delay (FID) was zero-filled to 131,072 complex data points and an exponential window function was applied with a line broadening factor of $1.0 \mathrm{~Hz}$ prior to Fourier transformation. The spectra were automatically phase and baseline corrected.

\section{Quality control, scaling and calibration of the NMR spectra} Further data processing was performed in Matlab $^{\circ}$ (R2009a; The Mathworks Inc., Natick, MA, USA) and described in Vaarhorst et al. [40]. In brief, the spectra and associated data were converted into Matlab files using in-house code. First, the spectra were combined into one file while removing superfluous information. For CPMG this included dropping the imaginary part of the spectrum, while for the JRES spectra the sum projection along the indirect dimension was taken. Quality control (QC) on the set of ${ }^{1} \mathrm{H}-\mathrm{NMR}$ spectra was carried out by examining a set of spectroscopic parameters such as shim values and intensity of the water signal, and subsequently visually inspecting the spectra. Spectra that failed the quality control were not included for further analysis. The remaining spectra were scaled with respect to the sensitivity of the receiver coil. This sensitivity is inversely proportional to the pulse length, which is dependent on the tuning of the RF coil. After subtracting a constant value as a simple baseline correction, the spectra were calibrated with respect to the anomeric resonance of $\alpha$-D-glucose $(\delta=5.23 \mathrm{ppm})$ [47]. Since there are small deviations of the signal position in the different ${ }^{1} \mathrm{H}$-NMR spectra, alignment was performed using the correlation optimized warping algorithm by Tomasi et al. [48]. This was performed actively for the CPMG spectra, after which the same warping was applied to the JRES projection. The peaks in the JRES projection were automatically deconvoluted by fitting the spectra with mixed Gauss-Lorentz line shapes using the Simplex method. As the fitting algorithm incidentally converges to a local minimum, values further from the median than three times the interquartile range were discarded. Using partial least square regression, the remaining signal intensities were used to build a linear model that predicts the intensities directly from the non-warped spectrum, yielding also reasonable values for the cases where the deconvolution or warping algorithms failed.

Finally, metabolites were assigned using information from the Human Metabolome Database (HMDB) and the Pearson correlation coefficients between the peak intensities [49].

\section{Statistical analyses and data processing}

Student's $t$-test and Chi-square tests were used to compare demographic characteristics between cases and controls. Raw ${ }^{1} \mathrm{H}-\mathrm{NMR}$ signal data were processed as follows. Values below [mean - 4*SD] and above $[$ mean $+4 * \mathrm{SD}]$ were filtered out. Then normality was assessed and data were $\log _{10}$-transformed when necessary, using SPSS software version 20.0 (SPSS Inc., IBM, Armonk, NY, USA). Signal data was adjusted for kinship by linear regression in GenABEL version 1.7-0, using $R$ version 2.14.2 ( $\mathrm{R}$ Foundation for Statistical Computing, Vienna, Austria) [50]. Finally, the residuals from this linear regression model were transformed into Z-scores to approximate normality using SPSS software version 25.0 (SPSS Inc., IBM, Armonk, NY, USA). To reduce the dimensionality of the data and due to possible correlations between the parameters, elastic net regression was used to select a subset of the most informative signals for: (1) lifetime migraine diagnosis, and (2) a diagnosis of active migraine (defined as having at least one severe migraine in the last 12 months). Of note, patients likely had many attacks in the last year as is typical in migraine patients when they still have migraines, but data are lacking to assess how many attacks they had and when the last attack was before blood withdrawal nor do we know whether they were on medication. Hence we consider our migraine cases a sample with "real-life variation" with respect to attack frequency and severity. The $R$ package glmnet was used with alpha set to 0.5 and 50 fold cross-validation using $\mathrm{R}$ software version 3.6.1 [51]. In this cross-validation step we validated the selection of the signals by performing our regression analysis on 50 randomly chosen samples of our study population. Elastic net regression reduces variance and error and increases bias and the predictive power, which leads to better long-term prediction. However, the inferential capability decreases, which makes interpretation difficult as there are no uncertainties in terms of confidence intervals or hypothesis testing.

In an attempt to interpret our findings, we performed subsequent regression models. Because we had to perform the regression models within the unique cohort the exact $p$-values of these models are no longer valid, although the results may provide at least some information whether metabolites may be involved. For the 
regression models we entered the metabolites of the metabolic profiles in a logistic regression model to determine the weights for each signal for this population. The linear predictor of the logistic regression model was used as a "weighted metabolite score" (sum of regression coefficients multiplied by the corresponding covariate values). This score was used in a second logistic regression analysis to calculate odds ratios (ORs), $p$-values and the proportion of explained variance. To determine whether we had to correct our logistic regression model we independently assessed the influence of sex, age, body mass index (BMI) and smoking status on the "weighted metabolite score", by visually inspecting stratification plots and performing a linear model, where the "weighted metabolite score" was modelled as a function of migraine status. We included age, sex, BMI and current smoking status as covariates in the logistic regression model. To validate the findings from the previous analysis we performed analysis of variance (ANOVA) in which we compared the performance of the full model with the identified scores for migraine with the performance of a model containing only information on age, sex, BMI and smoking.

\section{Results}

\section{Study population}

We conducted a case-control study with in the ERF population cohort and included 2088 participants in the study of which 360 were lifetime migraine patients and 1728 without severe headache served as controls. Eight-hour fasting serum samples were available from 313 migraine patients and 1512 controls that were used for ${ }^{1} \mathrm{H}$-NMR spectroscopy profiling (see Fig. 1).

\section{Signal detection, assignment and processing}

A total of 100 metabolite signals were detected in the JRES projection and quantified in the ${ }^{1} \mathrm{H}$-NMR spectra [37]. For 82 signals, metabolites could be assigned. These 82 signals represented 49 different metabolites (See Additional file 1 for signal assignment). The other 18 signals could not be annotated. In total, good-quality ${ }^{1} \mathrm{H}$-NMR spectra were obtained from 289 migraine patients and 1360 controls. For 19 signals (out of 100) outliers were removed and nine signals were $\log _{10^{-}}$ transformed (See Additional file 1). The remaining data points of the 100 signals were used for the association analyses with migraine.

\section{Demographic characteristics}

The demographic characteristics of the study population of whom good ${ }^{1} \mathrm{H}-\mathrm{NMR}$ data were obtained are shown in Table 1. Migraine patients tended to be younger $(p=0.013)$ and more often were female than controls $(p<0.001)$. In addition, lifetime migraine patients more often than controls were smokers $(44.6 \%$ cases vs. $35.1 \%$ controls $p=0.006)$. No difference in BMI was observed between cases and controls $(p=0.934)$. Of the 289 lifetime migraine patients, $150(52 \%)$ reported at least one severe migraine attack in the 12 months preceding the interview and were assigned to the group of "active migraine patients". The active migraine patients consisted of 124 women (83\%), had a mean age of 44 (SD \pm $11.4), 71(47.3 \%)$ were currently smoking and had a mean BMI of $26(\mathrm{SD} \pm 4.9)$. Next, we assessed the influence of age, sex, BMI and smoking (see Additional file 2) on the weighted metabolite score. All covariates showed to be of influence on the weighted metabolite score and were added to the logistic regression model.

\section{Association of metabolites with lifetime migraine diagnosis}

Elastic net regression analysis of all 289 migraine patients and 1360 controls for all 100 signals identified six ${ }^{1} \mathrm{H}-\mathrm{NMR}$ signals as the best prediction subset. These signals were representative of four different metabolites (isoleucine, methionine, 1,5-anhydrosorbitol and creatine) and one unknown signal (Table 2). Subsequent logistic regression analysis showed support for association (odds ratio $(\mathrm{OR})=2.72$; $95 \%$ confidence interval (CI) $1.97-3.75 ; p=1.28 \times 10^{-9}$ ) explaining $3.9 \%$ of the variance in migraine status (Nagelkerke $\mathrm{R}^{2}$ ). After correction for age, sex, BMI and smoking the association no longer showed support for association $(\mathrm{OR}=1.49$; 95\% CI 0.99-2.23; $p=0.051$ ).

Association of metabolites with active migraine diagnosis Next, we performed an elastic net regression on all 150 active migraine patients and 1360 controls for all 100 signals. This analysis identified 22 predictive signals. The subsequent logistic regression analysis was performed on 146 cases and 1343 controls, as not all subjects had sufficient signal data for all 22 signals. The regression showed support for association between the signal data and active migraine status $(\mathrm{OR}=2.72$; $95 \% \mathrm{CI} 2.09-3.54$; $p=1.35 \times 10^{-13}$ ) explaining $8.5 \%$ of the variance, this association remained after correction for sex, age, BMI and current smoking status $(\mathrm{OR}=1.84$; 95\% CI 1.34$\left.2.53 ; p=1.64 \times 10^{-4}\right)$ with a total explained variance of $12.3 \%$ (Nagelkerke $\mathrm{R}^{2}$ ). Hosmer and Lemeshow shows a good fit of the final model $(p=0.688)$. The outcome of our ANOVA analysis $\left(p=7.1 \times 10^{-5}\right)$ added to the evidence for involvement of these metabolites in active migraine patients. The majority of the 22 signals have been annotated to metabolites, but four remained unknown (Table 2). The known metabolites that were relevant to distinguish metabolic profile of migraine patients from controls were cholesterol, isoleucine, leucine, lipids $\left(\mathrm{CH} 2\right.$ and $\left.\mathrm{CH}^{*} 2 \mathrm{CH}=\mathrm{CH}\right)$, acetate, pyruvate, methionine, dimethylglycine, 1,5-anhydrosorbitol, valine, myoinositol, glucose, serine, creatinine, and proline. Our data 


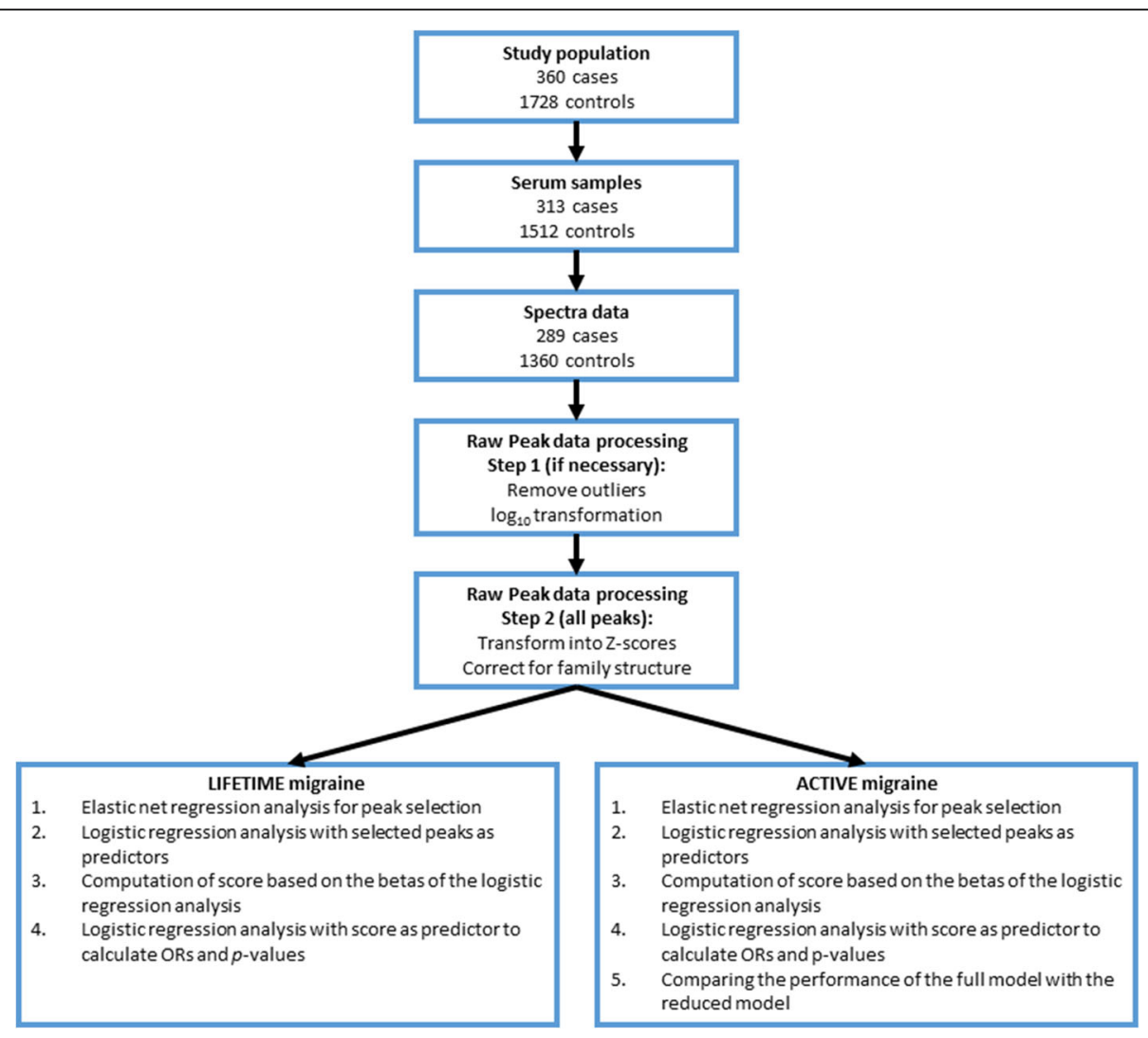

Fig. 1 Flow chart of the patient flow and analysis steps

suggests that there is a metabolic profile for active migraine that distinguishes them from controls even after correcting for age, sex, BMI and smoking status. Remarkable is that five of the six signals predictive for lifetime migraine status are also predictive for active migraine status (Table 2).

\section{Discussion}

Here we investigated metabolites identified by ${ }^{1} \mathrm{H}-\mathrm{NMR}$ spectroscopy in serum of migraine patients and controls to assess whether metabolic profiles can distinguish the two groups. We identified 22 metabolites that were predictive for active migraine and estimated that they would remain predictive after correction for age, sex, BMI and smoking status. Active migraine status was linked with metabolic profiles with more (22) metabolites, when compared with lifetime migraine (6), suggesting that active migraine patients may have a more disturbed metabolic profile compared to lifetime migraine patients, at least among the 100 measured metabolites. Although, based on our study, it is not possible to directly interpret the $p$-values nor to make association on an individual metabolite level among the total 22 compounds associated with active migraine, it is

Table 1 Demographic characteristics

\begin{tabular}{|c|c|c|c|c|c|}
\hline Variable & $\begin{array}{l}\text { Lifetime migraine patients } \\
(N=289)\end{array}$ & $\begin{array}{l}\text { Controls } \\
(N=1360)\end{array}$ & $p$-value & $\begin{array}{l}\text { Active migraine patients }{ }^{\mathrm{b}} \\
(N=150)\end{array}$ & $p$-value \\
\hline Age (years) & $46.5 \pm 12.1$ & $48.7 \pm 14.5$ & $0.013^{\mathrm{c*}}$ & $44.0 \pm 11.4$ & $<0.001^{\mathrm{C*}}$ \\
\hline Female sex (\%) & $220(76.1)$ & $673(49.5)$ & $<0.001^{d *}$ & $124(82.7)$ & $<0.001^{d *}$ \\
\hline BMl & $26.9 \pm 5.0$ & $26.8 \pm 4.6$ & $0.934^{c}$ & $26.3 \pm 4.9$ & $0.219^{c}$ \\
\hline Smoking (yes) (\%) & $129(44.9)$ & $481(36.0)$ & $0.006^{\mathrm{d} *}$ & $71(47.3)$ & $0.008^{\mathrm{d} *}$ \\
\hline MO patients & $163(56.4)$ & - & - & $77(51.3)$ & - \\
\hline
\end{tabular}

Values are expressed as absolute values and percentage or mean \pm SD. Numbers and proportions may not add up to total of 100 due to rounding or missing

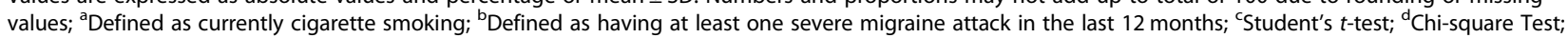
*Significant $p$-values $(p<0.05)$. Missing values in lifetime migraine patients for BMI $(n=2)$, smoking status $(n=2)$ and in controls for BMI $(n=24)$ smoking status $(n=27) . \mathrm{MO}=$ migraine without aura, $\mathrm{BMI}=$ body mass index 
Table $2{ }^{1} \mathrm{H}$-NMR signals associated with lifetime migraine patients and active migraine patients

\begin{tabular}{|c|c|c|c|}
\hline \multicolumn{2}{|c|}{ Lifetime migraine patients } & \multicolumn{2}{|c|}{ Active migraine patients } \\
\hline Metabolite & Chemical shift (ppm) & Metabolite & Chemical shift (ppm) \\
\hline Isoleucine & 0.92847 & Cholesterol & 0.89006 \\
\hline Isoleucine & 0.99919 & Isoleucine & 0.92847 \\
\hline Unknown & 1.40660 & Unknown & 0.95118 \\
\hline Methionine & 2.63742 & Leucine & 0.95702 \\
\hline 1,5-Anhydrosorbitol & 3.58832 & Isoleucine & 0.99919 \\
\hline \multirow[t]{17}{*}{ Creatine } & 3.92001 & Lipids $(\mathrm{CH} 2)^{\dagger}$ & 1.26482 \\
\hline & & Unknown & 1.40660 \\
\hline & & Acetate & 1.90859 \\
\hline & & Lipids $\left(\mathrm{CH}^{*} 2 \mathrm{CH}=\mathrm{CH}\right)^{\dagger}$ & 2.22215 \\
\hline & & Pyruvic acid & 2.36196 \\
\hline & & Methionine & 2.63742 \\
\hline & & Dimethylglycine & 2.91618 \\
\hline & & Unknown & 3.35396 \\
\hline & & 1,5-Anhydrosorbitol & 3.58832 \\
\hline & & Valine & 3.59782 \\
\hline & & Myoinositol & 3.62232 \\
\hline & & Glucose & 3.72103 \\
\hline & & Serine & 3.95567 \\
\hline & & Creatinine & 4.04386 \\
\hline & & Proline & 4.12106 \\
\hline & & Unknown & 4.50117 \\
\hline & & Glucose & 5.22921 \\
\hline
\end{tabular}

Ppm parts per million; ${ }^{\dagger}$ The term in parenthesis indicates the structural feature of the lipids measured by ${ }^{1} \mathrm{H}$-NMR spectroscopy

remarkable that the majority of these 22 metabolites have been (indirectly) implicated in migraine before. In our study, we found metabolites involved in lipid metabolism namely; cholesterol, and two types of lipids $(\mathrm{CH} 2$ and $\mathrm{CH}^{*} 2 \mathrm{CH}=\mathrm{CH}$ ). A number of studies have previously implicated lipid metabolism in migraine for instance, epidemiologic studies have shown that obesity is a risk factor for migraine and that there is a comorbidity of cerebrovascular and cardiovascular disease and migraine [52, 53]. Some studies found an elevated total cholesterol, LDL-cholesterol, or triglycerides, and decreased levels of HDL-cholesterol in migraine [54, 55], whereas several other studies found no significant differences in lipid profiles $[54,56]$. A recent meta-analysis encompassing 2800 migraine patients and 7353 controls from eight Dutch cohorts, using a different ${ }^{1} \mathrm{H}$-NMR metabolomics platform in a systematic approach, also showed alterations in HDL metabolism, in that study defined by a decreased level of lipoprotein A1 and a decreased free cholesterol to total lipid ratio in small HDL subspecies [55]. Neurovascular and endothelial dysfunction are believed to be an underlying cause for the increased risk in cerebrovascular and cardiovascular diseases in migraine patients $[57,58]$. At the basis of this involvement lies a possible higher prevalence of risk factors, such as hypertension and hyperlipidaemia, in migraine patients [57]. Also the involvement of lipids in migraine pathophysiology has been shown in various studies $[54,55]$. Regardless, the exact role lipids play is complex and needs further investigation.

Glucose is another metabolite we found that has previously been associated with migraine either directly or via metabolically associated pathways. Glucose levels and insulin metabolism, as well as mitochondrial dysfunction have been known to play a role in migraine pathology $[59,60]$. Still, no association was found between migraine and diabetes type 2 $[59,61,62]$. It has been suggested that outside attacks, migraine patients have an impaired insulin sensitivity and higher fasting plasma insulin levels compared to controls [63, 64]. Recently it was shown that glucose levels were higher during a spontaneous migraine attack compared to outside of an attack [65]. Both 1,5-anhydrosorbitol and myoinositol, which were part of our prediction model, are involved in glucose metabolism. 1,5-Anhydrosorbitol is a naturally occurring monosaccharide found in nearly all foods and myoinositol, which is a carbocyclic sugar that is abundant in 
brain and other mammalian tissues, is synthesized from glucose 6-phosphate. Pyruvate is the conjugate base of pyruvic acid and is a key intermediate in several metabolic pathways throughout the cell. Pyruvic acid can be produced from glucose through glycolysis and it can supply energy to the cell via the Krebs cycle in the mitochondria. One study has investigated the lactic and pyruvic acid levels in the plasma of the migraine patients it was shown that both were significantly higher in migraine patients than in normal controls [66].

In addition, multiple amino acids were part of our prediction model for active migraine status, namely leucine, isoleucine, methionine, valine, proline and serine. Over the last decades, multiple amino acids have been hypothesized to play a role in migraine pathophysiology [19]. Leucine, isoleucine and valine are branched-chain amino acids (BCAAs), BCAAs have emerged as potential biomarkers of disease as they are associated with risk of cardiovascular disease, end-stage renal failure, and ischemic stroke [67]. In a small study of 37 migraine patients and 40 controls elevated levels of isoleucine in blood serum were found [68]. A recent study investigated amine pathways in 20 patients with migraine without aura, and 20 healthy subjects in serum with liquid chromatography coupled to mass spectrometry (LC-MS) [69]. This LC-MS study found decreased levels of leucine, isoleucine and methionine in migraine patients compared to controls. The valine, proline and serine concentration was not assessed directly in this study [69]. Although glutamate/glutamine has been repeatedly linked to migraine [70, 71], in our study the levels of glutamine/glutamate were not part of the predictive profile for migraine status.

As far as we know the other metabolites we found to be associated with active migraine status (acetate, dimethylglycine and creatinine) have thus far not been associated with migraine. Acetate is a monocarboxylic acid anion, which is metabolized mostly in peripheral tissues. Dimethylglycine, which is a derivative of the amino acid glycine, but it can also be a by-product of the metabolism of choline. Dimethylglycine has been suggested as a treatment for mitochondrial diseases [72] and in that sense might be associated with the migraineglucose dysregulation. Creatine is involved in the conversion from adenosine diphosphate (ADP) back to ATP in muscle and is synthesized mainly in the liver from amino acids glycine and arginine.

We here identified a metabolite profile predictive for active migraine, a finding supported by the observation that several of its metabolites have already been reported in literature to be individually (in) directly associated with migraine. We would like to emphasize again that the focus of this study was to explore whether metabolite profiles can be linked to migraine status and less to show direct clinical relevance of individual metabolites.
A limitation of our study is that, the set of metabolites we studied using our metabolic profiling method covers only a small part of the human metabolome. Future, complementary, studies using different, more advanced, platforms may identify additional metabolites associated with migraine status. Additionally, in our study population we know to what extent patients are related and have the opportunity to correct for this. Future studies have to show to what extent our findings are also applicable to well-selected groups of migraine patients, for instance, with respect to frequency of attacks, time of last attack to blood withdrawal, possible comorbidities, etc. Another possible limitation is that in our study, model selection by elastic net regression was used for predictor selection to eliminate high correlations among predictors. This might lead to reduced transferability of prediction models, because correlation structures of predictors can vary between studies. Although we corrected for age, sex, BMI and smoking in our analysis, we cannot exclude a residual confounding effect of this variable nor of any other variable that we have not tested. Another limitation is that we used the same population for discovery of the associated signals and for assessing the magnitude of the association. Ideally, a replication study, to validate our findings, should be performed.

\section{Conclusions}

In conclusion, using hypothesis-free metabolic profiling, by measuring a large set of metabolites using ${ }^{1} \mathrm{H}-\mathrm{NMR}$ spectroscopy, we identified a metabolomic profile consisting of 22 metabolite signals (lipids, amino acids and metabolites of glucose metabolism) that was predictive for active migraine status.

\section{Abbreviations \\ ${ }^{1} \mathrm{H}-\mathrm{NMR}$ : Proton nuclear magnetic resonance spectroscopy; ERF: Erasmus Rucphen Family; JRES: J-resolved spectra; CPMG: Purcell-Meiboom-Gill; OR: Odds ratio; Cl: Confidence interval; CGRP: Calcitonin gene-related peptide}

\section{Supplementary Information}

The online version contains supplementary material available at https://doi. org/10.1186/s10194-021-01357-w.

Additional file 1. File with an overview of signals identified in the 2dimensional J-resolved ${ }^{1} \mathrm{H}-\mathrm{NMR}$ spectrum and performed transformations

Additional file 2. File with ratio stratification plots for sex, age BMI and smoking status in lifetime migraine patients and active migraine patients

\section{Acknowledgements}

Thanks to all study participants from the Erasmus Rucphen Family and their relatives, general practitioners, and neurologists for their contributions. We thank Dr. Oleg A. Mayboroda, from the Center for Proteomics and

Metabolomics (LUMC), in which the NMR analyses were done, for critical reading of the manuscript and Dr. Boukje de Vries for technical help and support.

\section{Authors' contributions}

AMJMvdM, GMT designed the study design. PH and AVEH were involved in the ${ }^{1} \mathrm{H}$-NMR measurements and/or annotation. PH, AVEH and LSV performed 
the statistical analyses. All authors contributed to the interpretation of results. AVEH made the figures and wrote the initial draft of the manuscript. All authors critically revised and approved the final version for submission.

\section{Funding}

This work was supported by grants from the Netherlands Organization for Scientific Research (NWO) (907-00-217, G.M.T; VIDI 91711319, G.M.T.); the Centre for Medical Systems Biology.

(CMSB) and Netherlands Consortium for Systems Biology (NCSB), both within the framework of the Netherlands Genomics Initiative (NGI)/NWO (to A.M.J.M.v.d.M.); and the FP7 EU project EUROHEADPAIN (no. 602633) (to A.M.J.M.v.d.M. and G.M.T.). They had no role in the design or conduct of the study. The ERF study is part of EUROSPAN (European Special Populations Research Network) FP6 STRP (no.018947 LSHG-CT-2006-01947) and also received funding from the European Community's Seventh Framework Programme (FP7/2007-2013)/grant agreement HEALTH-F4-2007-201413 by the European Commission under the programme "Quality of Life and Management of the Living Resources" of 5th Framework Programme (no. QLG2CT-2002-01254) as well as FP7 project EUROHEADPAIN (nr 602633).

\section{Availability of data and materials}

The data used and/or analysed during the current study are available from the corresponding author on reasonable request.

\section{Declarations}

\section{Ethics approval and consent to participate}

The study was approved by the medical ethics committee of Erasmus University Medical Centre. All subjects provided written informed consent prior to the study.

\section{Consent for publication}

Not applicable.

\section{Competing interests}

The authors declare that they have no competing interests.

\section{Author details}

${ }^{1}$ Departments of Human Genetics, Leiden University Medical Centre, Leiden, The Netherlands. ${ }^{2}$ Department of Neurology, Leiden University Medical Centre, Leiden, The Netherlands. ${ }^{3}$ Department of Clinical Genetics, Genome Diagnostic laboratory, Amsterdam Reproduction \& Development research institute, Amsterdam University Medical Centre, Amsterdam, The Netherlands. ${ }^{4}$ Einthoven Laboratory for Experimental Vascular Medicine, Leiden University Medical Centre, Leiden, The Netherlands. ${ }^{5}$ Department of Internal Medicine, Division of Endocrinology, Leiden University Medical Centre, Leiden, The Netherlands. ${ }^{6}$ Department of Epidemiology, Erasmus Medical Centre, Rotterdam, The Netherlands. ${ }^{7}$ Nuffield Department of Population Health, Oxford University, Oxford, UK.

\section{Received: 2 April 2021 Accepted: 10 November 2021} Published online: 24 November 2021

\section{References}

1. GDB 2019 Diseases and Injuries Collaborators (2020) Global burden of 369 diseases and injuries in 204 countries and territories, 1990-2019: a systematic analysis for the Global Burden of Disease Study 2019. Lancet 396: 1204-1222

2. Launer LJ, Terwindt GM, Ferrari MD (1999) The prevalence and characteristics of migraine in a population-based cohort: the GEM study. Neurology. 53(3):537-542. https://doi.org/10.1212/WNL.53.3.537

3. (2018) Headache classification Committee of the International Headache Society (IHS) the international classification of headache disorders, 3rd edition. Cephalalgia. 38(1):1-211. https://doi.org/10.1177/0333102417738202

4. Ferrari MD, Klever RR, Terwindt GM, Ayata C, van den Maagdenberg AM (2015) Migraine pathophysiology: lessons from mouse models and human genetics. Lancet Neurol 14(1):65-80. https://doi.org/10.1016/S1474-4422(14 )70220-0

5. Wang TJ, Larson MG, Vasan RS, Cheng S, Rhee EP, McCabe E, Lewis GD, Fox CS, Jacques PF, Fernandez C, O'Donnell CJ, Carr SA, Mootha VK, Florez JC, Souza A, Melander O, Clish CB, Gerszten RE (2011) Metabolite profiles and the risk of developing diabetes. Nat Med 17(4):448-453. https://doi.org/10.1 038/nm.2307

6. Kaddurah-Daouk R, Krishnan KR (2009) Metabolomics: a global biochemical approach to the study of central nervous system diseases.

Neuropsychopharmacology. 34(1):173-186. https://doi.org/10.1038/npp.2 008.174

7. Orešič M, Hyötyläinen T, Herukka SK, Sysi-Aho M, Mattila I, Seppänan-Laakso T, Julkunen V, Gopalacharyulu PV, Hallikainen M, Koikkalainen J, Kivipelto M, Helisalmi S, Lötjönen J, Soininen H (2011) Metabolome in progression to Alzheimer's disease. Transl Psychiatry 1(12):e57. https://doi.org/10.1038/tp.2 011.55

8. Patel S, Ahmed S (2015) Emerging field of metabolomics: big promise for cancer biomarker identification and drug discovery. J Pharm Biomed Anal 107:63-74. https://doi.org/10.1016/j.jpba.2014.12.020

9. Shah SH, Sun JL, Stevens RD, Bain JR, Muehlbauer MJ, Pieper KS et al (2012) Baseline metabolomic profiles predict cardiovascular events in patients at risk for coronary artery disease. Am Heart J 163:844-850.e841

10. Deng Y, Huang C, Su J, Pan CW, Ke C (2021) Identification of biomarkers for essential hypertension based on metabolomics. Nutr Metab Cardiovasc Dis 31(2):382-395. https://doi.org/10.1016/j.numecd.2020.11.023

11. Chan D, Ng LL (2010) Biomarkers in acute myocardial infarction. BMC Med 8(1):34. https://doi.org/10.1186/1741-7015-8-34

12. Riely GJ, Marks J, Pao W (2009) KRAS mutations in non-small cell lung cancer. Proc Am Thorac Soc 6(2):201-205. https://doi.org/10.1513/pats.2 00809-107LC

13. De Vries B, Haan J, Frants RR, Van den Maagdenberg AM, Ferrari MD (2006) Genetic biomarkers for migraine. Headache. 46(7):1059-1068. https://doi. org/10.1111/j.1526-4610.2006.00499.x

14. van Dongen RM, Zielman $R$, Noga M, Dekkers OM, Hankemeier T, van den Maagdenberg AM et al (2017) Migraine biomarkers in cerebrospinal fluid: a systematic review and meta-analysis. Cephalalgia. 37(1):49-63. https://doi. org/10.1177/0333102415625614

15. Gormley P, Anttila V, Winsvold BS, Palta P, Esko T, Pers TH et al (2016) Metaanalysis of 375,000 individuals identifies 38 susceptibility loci for migraine. Nat Genet 48(8):856-866. https://doi.org/10.1038/ng.3598

16. Schwedt TJ, Chiang CC, Chong CD, Dodick DW. Functional MRI of migraine Lancet Neurol. 2015;14:81-91.

17. Frederiksen SD, Bekker-Nielsen Dunbar M, Snoer AH, Deen M, Edvinsson L (2020) Serotonin and neuropeptides in blood from episodic and chronic migraine and cluster headache patients in case-control and case-crossover settings: a systematic review and Meta-analysis. Headache. 60(6):1132-1164. https://doi.org/10.1111/head.13802

18. Ferroni P, Barbanti P, Spila A, Fratangeli F, Aurilia C, Fofi L, Egeo G, Guadagni $F$ (2019) Circulating biomarkers in migraine: new opportunities for precision medicine. Curr Med Chem 26(34):6191-6206. https://doi.org/10.2174/092 9867325666180622122938

19. Ferrari MD, Odink J, Bos KD, Malessy MJ, Bruyn GW (1990) Neuroexcitatory plasma amino acids are elevated in migraine. Neurology. 40(10):1582-1586. https://doi.org/10.1212/WNL.40.10.1582

20. Martinez F, Castillo J, Rodriguez JR, Leira R, Noya M (1993) Neuroexcitatory amino acid levels in plasma and cerebrospinal fluid during migraine attacks. Cephalalgia. 13(2):89-93. https://doi.org/10.1046/j.1468-2982.1993.1302089.x

21. Guldiken S, Guldiken B, Demir M, Kabayel L, Ozkan H, Turgut N, Hunkar R, Kat S (2011) Soluble CD40 ligand and prolactin levels in migraine patients during interictal period. J Headache Pain 12(3):355-360. https://doi.org/10.1 007/s10194-011-0306-8

22. Vanmolkot FH, de Hoon JN (2007) Increased C-reactive protein in young adult patients with migraine. Cephalalgia. 27(7):843-846. https://doi.org/1 0.1111/j.1468-2982.2007.01324.x

23. Pavelek Z, Soucek O, Krejsek J, Sobisek L, Klimova B, Masopust J et al (2020) The role of the immune system and the biomarker CD3 + CD4 + CD45RACD62L- in the pathophysiology of migraine. Sci Rep 10(1):12277. https://doi. org/10.1038/s41598-020-69285-4

24. Fusayasu E, Kowa H, Takeshima T, Nakaso K, Nakashima K (2007) Increased plasma substance $P$ and CGRP levels, and high ACE activity in migraineurs during headache-free periods. Pain. 128(3):209-214. https://doi.org/10.1016/ j.pain.2006.09.017

25. Cernuda-Morollon E, Larrosa D, Ramon C, Vega J, Martinez-Camblor P, Pascual J (2013) Interictal increase of CGRP levels in peripheral blood as a biomarker for chronic migraine. Neurology. 81(14):1191-1196. https://doi. org/10.1212/WNL.0b013e3182a6cb72 
26. Cernuda-Morollón E, Martínez-Camblor P, Alvarez R, Larrosa D, Ramón C, Pascual J (2015) Increased VIP levels in peripheral blood outside migraine attacks as a potential biomarker of cranial parasympathetic activation in chronic migraine. Cephalalgia. 35(4):310-316. https://doi.org/10.1177/03331 02414535111

27. Hamed SA, Hamed EA, Ezz Eldin AM, Mahmoud NM (2010) Vascular risk factors, endothelial function, and carotid thickness in patients with migraine: relationship to atherosclerosis. J Stroke Cerebrovasc Dis 19(2):92103. https://doi.org/10.1016/j.jstrokecerebrovasdis.2009.04.007

28. Kurth T, Ridker PM, Buring JE (2008) Migraine and biomarkers of cardiovascular disease in women. Cephalalgia. 28(1):49-56. https://doi.org/1 0.1111/j.1468-2982.2007.01467.x

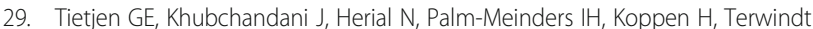
GM, van Buchem MA, Launer LJ, Ferrari MD, Kruit MC (2018) Migraine and vascular disease biomarkers: a population-based case-control study. Cephalalgia. 38(3):511-518. https://doi.org/10.1177/0333102417698936

30. Edvinsson L, Haanes KA, Warfvinge K, Krause DN (2018) CGRP as the target of new migraine therapies - successful translation from bench to clinic. Nat Rev Neurol 14(6):338-350. https://doi.org/10.1038/s41582-018-0003-1

31. Edvinsson L, Warfvinge $K$ (2019) Recognizing the role of CGRP and CGRP receptors in migraine and its treatment. Cephalalgia. 39(3):366-373. https:// doi.org/10.1177/0333102417736900

32. Ramon C, Cernuda-Morollon E, Pascual J (2017) Calcitonin gene-related peptide in peripheral blood as a biomarker for migraine. Curr Opin Neurol 30(3):281-286. https://doi.org/10.1097/WCO.0000000000000440

33. Greco R, De Icco R, Demartini C, Zanaboni AM, Tumelero E, Sances G et al (2020) Plasma levels of CGRP and expression of specific microRNAs in blood cells of episodic and chronic migraine subjects: towards the identification of a panel of peripheral biomarkers of migraine? J Headache Pain 21(1):122. https://doi.org/10.1186/s10194-020-01189-0

34. Hagen K, Stovner LJ, Zwart JA (2020) High sensitivity C-reactive protein and risk of migraine in a 11-year follow-up with data from the Nord-Trondelag health surveys 2006-2008 and 2017-2019. J Headache Pain 21(1):67. https:// doi.org/10.1186/s10194-020-01142-1

35. Dunn WB, Broadhurst D, Begley P, Zelena E, Francis-Mclntyre S, Anderson N et al (2011) Procedures for large-scale metabolic profiling of serum and plasma using gas chromatography and liquid chromatography coupled to mass spectrometry. Nat Protoc 6(7):1060-1083. https://doi.org/10.1038/ nprot.2011.335

36. Stam AH, de Vries B, Janssens AC, Vanmolkot KR, Aulchenko YS, Henneman $P$ et al (2010) Shared genetic factors in migraine and depression: evidence from a genetic isolate. Neurology. 74(4):288-294. https://doi.org/10.1212/ WNL.0b013e3181cbcd19

37. Aulchenko YS, Heutink P, Mackay I, Bertoli-Avella AM, Pullen J, Vaessen N, Rademaker TAM, Sandkuijl LA, Cardon L, Oostra B, van Duijn CM (2004) Linkage disequilibrium in young genetically isolated Dutch population. Eur J Hum Genet 12(7):527-534. https://doi.org/10.1038/sj.ejhg.5201188

38. Sleegers K, de Koning I, Aulchenko YS, van Rijn MJ, Houben MP, Croes EA et al (2007) Cerebrovascular risk factors do not contribute to genetic variance of cognitive function: the ERF study. Neurobiol Aging 28(5):735741. https://doi.org/10.1016/i.neurobiolaging.2006.03.012

39. Headache Classification Subcommittee of the International Headache, S. The International Classification of Headache Disorders: 2nd edition. Cephalalgia: an international journal of headache. 2004;24 Suppl 1:9-160

40. Vaarhorst AA, Verhoeven A, Weller CM, Bohringer S, Goraler S, Meissner A et al (2014) A metabolomic profile is associated with the risk of incident coronary heart disease. Am Heart J 168(1):45-52 e47. https://doi.org/10.101 6/j.ahj.2014.01.019

41. Findeisen M, Brand T, Berger S (2007) A H-1-NMR thermometer suitable for cryoprobes. Magn Reson Chem 45(2):175-178. https:/doi.org/10.1002/mrc.1941

42. Wu PSC, Otting G (2005) Rapid pulse length determination in highresolution NMR. J Magn Reson 176(1):115-119. https://doi.org/10.1016/j. jmr.2005.05.018

43. Price WS (1999) Water signal suppression in NMR spectroscopy. Annu Rep NMR Spectrosc 38:289-354. https://doi.org/10.1016/S0066-4103(08)60040-X

44. Aue WP, Karhan J, Ernst RR (1976) Homonuclear broad-band decoupling and 2-dimensional J-resolved Nmr-spectroscopy. J Chem Phys 64(10):42264227. https://doi.org/10.1063/1.431994

45. Meiboom S, Gill D (1958) Modified spin-Echo method for measuring nuclear relaxation times. Rev Sci Instrum 29(8):688-691. https://doi.org/10.1063/1.1 716296
46. Nicholson JK, Foxall PJD, Spraul M, Farrant RD, Lindon JC (1995) 750-Mhz H1 and $\mathrm{H}-1-\mathrm{C}-13 \mathrm{Nmr}-\mathrm{spectroscopy}$ of human blood-plasma. Anal Chem 67(5):793-811. https://doi.org/10.1021/ac00101a004

47. Maclntyre DA, Jimenez B, Lewintre EJ, Martin CR, Schafer H, Ballesteros CG et al (2010) Serum metabolome analysis by H-1-NMR reveals differences between chronic lymphocytic leukaemia molecular subgroups. Leukemia. 24(4):788-797. https://doi.org/10.1038/leu.2009.295

48. Tomasi G, van den Berg F, Andersson C (2004) Correlation optimized warping and dynamic time warping as preprocessing methods for chromatographic data. J Chemom 18(5):231-241. https://doi.org/10.1002/ cem.859

49. Wishart DS, Jewison T, Guo AC, Wilson M, Knox C, Liu YF, Djoumbou Y, Mandal R, Aziat F, Dong E, Bouatra S, Sinelnikov I, Arndt D, Xia J, Liu P, Yallou F, Bjorndahl T, Perez-Pineiro R, Eisner R, Allen F, Neveu V, Greiner R, Scalbert A (2013) HMDB 3.0-the human metabolome database in 2013. Nucleic Acids Res 41(Database issue):D801-D807. https://doi.org/10.1093/na r/gks1065

50. Aulchenko YS, Ripke S, Isaacs A, Van Duijn CM (2007) GenABEL: an R library for genome-wide association analysis. Bioinformatics. 23(10):1294-1296. https://doi.org/10.1093/bioinformatics/btm108

51. Friedman J, Hastie T, Tibshirani R (2010) Regularization paths for generalized linear models via coordinate descent. J Stat Softw 33(1):1-22. https://doi. org/10.18637/jss.v033.i01

52. Bigal ME, Lipton RB (2006) Obesity is a risk factor for transformed migraine but not chronic tension-type headache. Neurology. 67(2):252-257. https:// doi.org/10.1212/01.wnl.0000225052.35019.f9

53. Linstra KM, Ibrahimi K, Terwindt GM, Wermer MJ, MaassenVanDenBrink A (2017) Migraine and cardiovascular disease in women. Maturitas. 97:28-31. https://doi.org/10.1016/j.maturitas.2016.12.008

54. Tietjen GE, Khubchandani J (2015) Vascular biomarkers in migraine. Cephalalgia. 35(2):95-117. https://doi.org/10.1177/0333102414544976

55. Onderwater GLJ, Ligthart L, Bot M, Demirkan A, Fu J, van der Kallen CJH, Vijfhuizen LS, Pool R, Liu J, Vanmolkot FHM, Beekman M, Wen KX, Amin N, Thesing CS, Pijpers JA, Kies DA, Zielman R, de Boer I, van Greevenbroek MMJ, Arts ICW, Milaneschi Y, Schram MT, Dagnelie PC, Franke L, Ikram MA, Ferrari MD, Goeman JJ, Slagboom PE, Wijmenga C, Stehouwer CDA Boomsma DI, van Duijn CM, Penninx BW, 't Hoen PAC, Terwindt GM, van den Maagdenberg AMJM, on behalf of the BBMRI Metabolomics Consortium (2019) Large-scale plasma metabolome analysis reveals alterations in HDL metabolism in migraine. Neurology. 92(16):e1899-e1911. https://doi.org/10.1212/WNL.0000000000007313

56. Rubino E, Vacca A, Govone F, Gai A, Boschi S, Zucca M, de Martino P, Gentile S, Pinessi L, Rainero I (2017) Investigating the role of adipokines in chronic migraine. Cephalalgia. 37(11):1067-1073. https://doi.org/10.1177/ 0333102416665871

57. Bigal ME, Kurth T, Hu H, Santanello N, Lipton RB (2009) Migraine and cardiovascular disease: possible mechanisms of interaction. Neurology. 72(21):1864-1871. https://doi.org/10.1212/WNL.0b013e3181a71220

58. Paolucci M, Altamura C, Vernieri F (2021) The role of endothelial dysfunction in the pathophysiology and cerebrovascular effects of migraine: a narrative review. J Clin Neurol 17(2):164-175. https://doi.org/10.3988/jen.2021.17.2.164

59. Rainero I, Govone F, Gai A, Vacca A, Rubino E (2018) Is migraine primarily a Metaboloendocrine disorder? Curr Pain Headache Rep 22(5):36. https://doi. org/10.1007/s11916-018-0691-7

60. Yorns WR Jr, Hardison HH (2013) Mitochondrial dysfunction in migraine. Semin Pediatr Neurol 20(3):188-193. https//doi.org/10.1016/j.spen.2013.09.002

61. Burch RC, Rist PM, Winter AC, Buring JE, Pradhan AD, Loder EW, Kurth T (2012) Migraine and risk of incident diabetes in women: a prospective study. Cephalalgia. 32(13):991-997. https:/doi.org/10.1177/0333102412453954

62. López-de-Andrés A, Luis Del Barrio J, Hernández-Barrera V, de Miguel-Díez J, Jimenez-Trujillo I, Martinez-Huedo MA et al (2018) Migraine in adults with diabetes; is there an association? Results of a population-based study. Diabetes Metab Syndr Obes 11:367-374. https://doi.org/10.2147/DMSO.S170253

63. Cavestro C, Rosatello A, Micca G, Ravotto M, Marino MP, Asteggiano G et al (2007) Insulin metabolism is altered in migraineurs: a new pathogenic mechanism for migraine? Headache. 47(10):1436-1442. https://doi.org/1 0.1111/j.1526-4610.2007.00719.x

64. Rainero I, Limone P, Ferrero M, Valfrè W, Pelissetto C, Rubino E, Gentile S, Lo Giudice R, Pinessi L (2005) Insulin sensitivity is impaired in patients with migraine. Cephalalgia. 25(8):593-597. https://doi.org/10.1111/j.1468-2982.2 005.00928.x 
65. Zhang DG, Amin FM, Guo S, Vestergaard MB, Hougaard A, Ashina M (2020) Plasma glucose levels increase during spontaneous attacks of migraine with and without Aura. Headache. 60(4):655-664. https://doi.org/10.1111/head.13760

66. Okada H, Araga S, Takeshima T, Nakashima K (1998) Plasma lactic acid and pyruvic acid levels in migraine and tension-type headache. Headache. 38(1): 39-42. https://doi.org/10.1046/j.1526-4610.1998.3801039.x

67. Batch BC, Hyland K, Svetkey LP (2014) Branch chain amino acids: biomarkers of health and disease. Curr Opin Clin Nutr Metab Care 17(1):86-89. https:// doi.org/10.1097/MCO.0000000000000010

68. Domitrz I, Koter MD, Cholojczyk M, Domitrz W, Baranczyk-Kuzma A, Kaminska A (2015) Changes in serum amino acids in migraine patients without and with Aura and their possible usefulness in the study of migraine pathogenesis. CNS Neurol Disord Drug Targets 14(3):345-349. https://doi.org/10.2174/1871527314666150225144300

69. Ren C, Liu J, Zhou J, Liang H, Wang Y, Sun Y, Ma B, Yin Y (2018) Low levels of serum serotonin and amino acids identified in migraine patients. Biochem Biophys Res Commun 496(2):267-273. https://doi.org/10.1016/j. bbrc.2017.11.203

70. Cananzi AP, Dandrea G, Perini F, Zamberlan F, Welch KMA (1995) Platelet and plasma-levels of glutamate and glutamine in migraine with and without Aura. Cephalalgia. 15(2):132-135. https://doi.org/10.1046/j.1468-2 982.1995.015002132.x

71. Zielman R, Wijnen JP, Webb A, Onderwater GLJ, Ronen I, Ferrari MD, Kan HE, Terwindt GM, Kruit MC (2017) Cortical glutamate in migraine. Brain. 140(7):1859-1871. https://doi.org/10.1093/brain/awx130

72. Pfeffer G, Majamaa K, Turnbull DM, Thorburn D, Chinnery PF (2012) Treatment for mitochondrial disorders. Cochrane Database Syst Rev 2012: Cd004426

\section{Publisher's Note}

Springer Nature remains neutral with regard to jurisdictional claims in published maps and institutional affiliations.

Ready to submit your research? Choose BMC and benefit from:

- fast, convenient online submission

- thorough peer review by experienced researchers in your field

- rapid publication on acceptance

- support for research data, including large and complex data types

- gold Open Access which fosters wider collaboration and increased citations

- maximum visibility for your research: over $100 \mathrm{M}$ website views per year

At $\mathrm{BMC}$, research is always in progress.

Learn more biomedcentral.com/submissions 